PREPARED FOR THE U.S. DEPARTMENT OF ENERGY, UNDER CONTRACT DE-AC02-76CH03073

PPPL-3954

PPPL-3954

UC-70

Observation of a High Performance Operating Regime with Small Edge-localized Modes in the National Spherical Torus Experiment

by

R. Maingi, K. Tritz, E.D. Fredrickson, J.E. Menard, S.A. Sabbagh, D. Stutman, M.G. Bell, R.E. Bell, C.E. Bush, D.A. Gates, D.W. Johnson, R. Kaita, S.M. Kaye, H.W. Kugel, B.P. LeBlanc, D. Mueller, R. Raman, A.L. Roquemore, and V.A. Soukhanovskii

May 2004
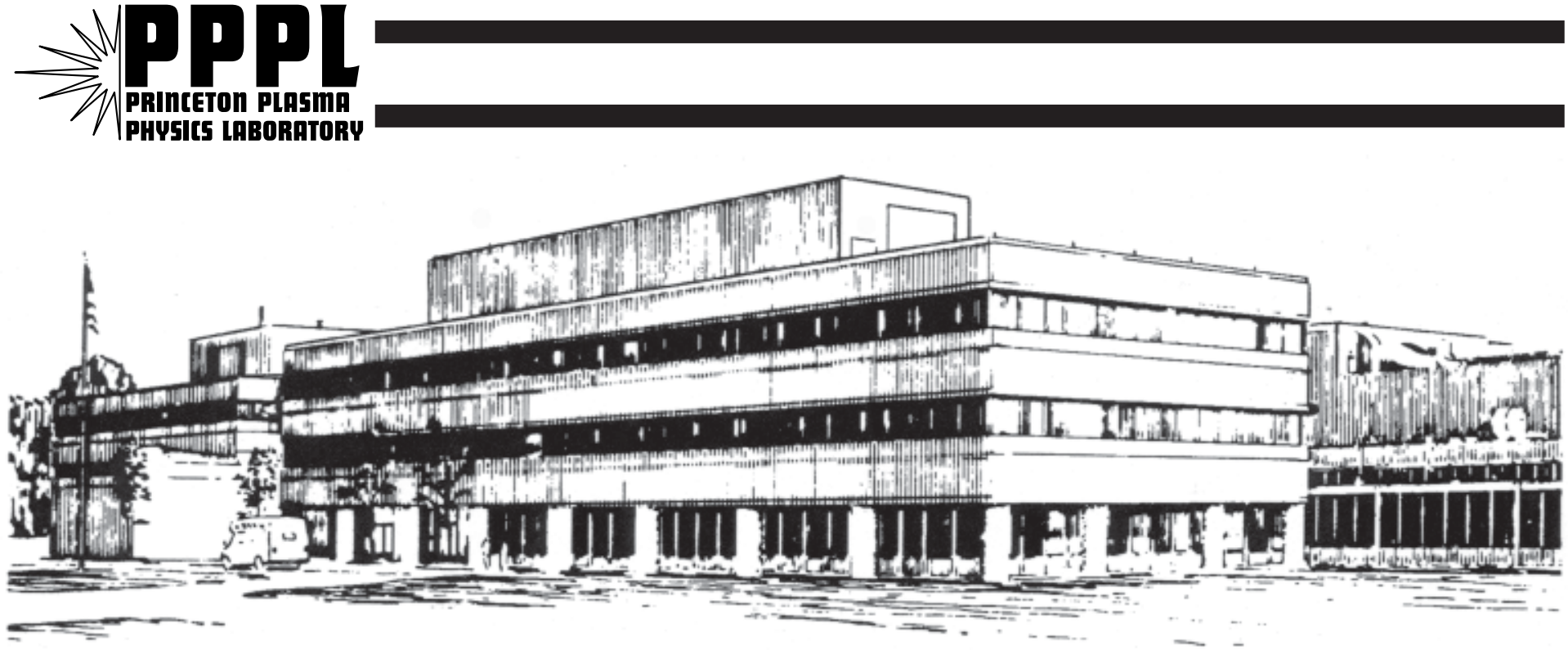

PRINCETON PLASMA PHYSICS LABORATORY PRINCETON UNIVERSITY, PRINCETON, NEW JERSEY 


\section{PPPL Reports Disclaimer}

This report was prepared as an account of work sponsored by an agency of the United States Government. Neither the United States Government nor any agency thereof, nor any of their employees, makes any warranty, express or implied, or assumes any legal liability or responsibility for the accuracy, completeness, or usefulness of any information, apparatus, product, or process disclosed, or represents that its use would not infringe privately owned rights. Reference herein to any specific commercial product, process, or service by trade name, trademark, manufacturer, or otherwise, does not necessarily constitute or imply its endorsement, recommendation, or favoring by the United States Government or any agency thereof. The views and opinions of authors expressed herein do not necessarily state or reflect those of the United States Government or any agency thereof.

\section{Availability}

This report is posted on the U.S. Department of Energy's Princeton Plasma Physics Laboratory Publications and Reports web site in Fiscal Year 2004. The home page for PPPL Reports and Publications is: http://www.pppl.gov/pub_report/

DOE and DOE Contractors can obtain copies of this report from:

U.S. Department of Energy

Office of Scientific and Technical Information

DOE Technical Information Services (DTIS)

P.O. Box 62

Oak Ridge, TN 37831

Telephone: (865) 576-8401

Fax: (865) 576-5728

Email: reports@adonis.osti.gov

This report is available to the general public from:

National Technical Information Service

U.S. Department of Commerce

5285 Port Royal Road

Springfield, VA 22161

Telephone: $1-800-553-6847$ or

(703) $605-6000$

Fax: (703) 321-8547

Internet: http://www.ntis.gov/ordering.htm 


\title{
Observation of a High Performance Operating Regime with Small Edge-Localized Modes in the National Spherical Torus Experiment
}

R. Maingi ${ }^{\mathrm{a}}$, K. Tritz ${ }^{\mathrm{b}}$, E.D. Fredrickson ${ }^{\mathrm{c}}$, J.E. Menard ${ }^{\mathrm{c}}$, S.A. Sabbagh ${ }^{\mathrm{d}}$, D. Stutman ${ }^{\mathrm{b}}$, M.G. Bell $^{c}$, R.E. Bell ${ }^{c}$, C.E. Bush ${ }^{\text {a }}$, D.A. Gates ${ }^{\mathrm{c}}$, D.W. Johnson ${ }^{\mathrm{c}}$, R. Kaita ${ }^{\mathrm{c}}$, S.M. Kaye ${ }^{\mathrm{c}}$, H.W. Kugel $^{\text {c }}$, B.P. LeBlanc ${ }^{c}$, D. Mueller ${ }^{c}$, R. Raman ${ }^{\mathrm{e}}$, A.L. Roquemore ${ }^{\mathrm{c}}$, V.A. Soukhanovskii ${ }^{\mathrm{f}}$

${ }^{a}$ Oak Ridge National Laboratory, Oak Ridge TN, 37831 USA

${ }^{b}$ Johns Hopkins University, Baltimore, MD, USA

'Princeton Plasma Physics Laboratory, PO Box 451, Princeton, NJ, 08543 USA

${ }^{d}$ Columbia University, New York, NY, USA

${ }^{e}$ University of Washington, Seattle WA, USA

${ }^{f}$ Lawrence Livermore National Laboratory, Livermore CA USA

PACS numbers: 52.55.Fa

\begin{abstract}
$\underline{\text { Abstract }}$
We report observation of a high performance scenario in the National Spherical Torus Experiment with very small edge-localized modes (ELMs). These ELMs have no measurable impact on stored energy and are consistent with high bootstrap current operation with line average density approaching Greenwald scaling. The ELM perturbation is observed to typically originate near the lower divertor region, as opposed to the outer midplane for ELMs described in the literature. If extrapolable, this scenario would provide an attractive operating regime for next step fusion experiments.
\end{abstract}


Introduction - The desire for high performance operating regimes with few or no edge localized modes (ELMs) has been a high priority in nuclear fusion research. The baseline operating scenario for the International Thermonuclear Experimental Reactor (ITER) relies on H-Mode confinement and profiles ${ }^{1}$. In most $\mathrm{H}$-mode discharges in conventional aspect ratio tokamaks, ELMs are observed, which serve to flush fuel and impurity particles from the edge plasma into the scrape-off layer and divertor plasma. This periodic edge ejection results in transiently high power and particle loads to the plasma facing components (PFC). The best plasma performance is often realized in the Type I ELM regime (which is ITER's baseline scenario), but the type I ELM typically results in larger heat pulses than other ELM types ${ }^{2}$. Such transient PFC loading is tolerable in present day machines, but extrapolations show severe PFC damage resulting in larger, higher power density machines (such as ITER) when the ELM power loading exceeds material dependent limits ${ }^{3}$.

Several high performance regimes without ELMs have been identified in conventional aspect ratio tokamaks. The QH-mode is a high performance, largely ELMfree regime discovered ${ }^{4}$ on the DIII-D tokamak and recently reproduced in other devices. The QH-mode scenario requires neutral beam injection (NBI) counter to the direction of plasma current $\left(\mathrm{I}_{\mathrm{p}}\right)$, low density, and relies on the presence of an edge harmonic oscillation for particle control. The EDA H-mode has been identified by the Alcator CMOD group, and it relies on a quasi-coherent MHD mode in the vicinity of the separatrix for particle control ${ }^{5}$. The EDA H-mode bears strong resemblance to the earlier PDX forced density rise scenario, another high performance scenario with small ELMs ${ }^{6}$. We note also the recent success at generating high performance discharges with no/few large ELMs using a stochastic boundary layer in DIII-D, which also provided good density $\operatorname{control}^{7}$. The operating regime achieved in the National Spherical Torus Experiment (NSTX) and reported here is distinct from all of these: 1) there is no counter injection or edge harmonic oscillation as in $\mathrm{QH}$-mode, 2) there is no quasi-coherent mode in the edge plasma as in EDA H-mode, and 3) no stochastic boundary technique was used to suppress ELMs. In addition the ELMs themselves appear significantly different from ELM types in the literature. Hence this regime provides another small ELM regime for possible use in large fusion devices to provide density control without the significant heat 
flux transients associated with conventional type I ELMs and without the performance degradation observed in Type III ELMs ${ }^{8}$ (i.e. no degradation comparing type I and the small ELM discharges in NSTX). We refer to the perturbations in NSTX as type V ELMs.

Description of high performance regime - The NSTX is a medium-sized, low aspect ratio spherical tokamak ${ }^{9}$ with the following parameters: major radius $\mathrm{R}=0.85 \mathrm{~m}$, minor radius $\mathrm{a}=0.67 \mathrm{~m}, \mathrm{R} / \mathrm{a} \geq 1.26$, toroidal field $\mathrm{B}_{\mathrm{t}} \square 0.6 \mathrm{~T}$, with up to $7 \mathrm{MW}$ of NBI power $\left(\mathrm{P}_{\mathrm{NBI}}\right)$ and $6 \mathrm{MW}$ of radio-frequency heating. The basic characteristics of the NSTX high performance, small ELM regime are shown in Fig. 1 for a lower-single null diverted discharge with $\mathrm{I}_{\mathrm{p}}=0.8 \mathrm{MA}, \mathrm{B}_{\mathrm{t}}=0.5 \mathrm{~T}, \mathrm{P}_{\mathrm{NBI}}=4.1 \mathrm{MW}$, elongation $\square \sim 1.9$, lower triangularity $\square_{\mathrm{L}} \sim 0.5$, and upper triangularity $\square_{U} \sim 0.3$. The line density continuously rises after the H-mode transition at $\mathrm{t}=230 \mathrm{~ms}$ (Fig. 1b). Type V ELMs with a frequency $\sim 400$ $\mathrm{Hz}$ can be observed on the lower divertor $\mathrm{D}_{\square}$ starting at $\mathrm{t} \sim 340 \mathrm{~ms}$, although a few irregularly spaced type V ELMs are observed near 290 and $320 \mathrm{~ms}$. Gas puffing from the center stack lasts throughout the discharge (Fig. 1c); the combination of this fueling and the NBI particle source contribute to the observed density rise. The stored energy remains flat for about $370 \mathrm{~ms}$ or $\sim 7$ energy confinement times $\left(\square_{\mathrm{E}}\right)$, and the confinement enhancement over ITER-89P scaling ${ }^{10}$ is steady at $\sim 2.3$. For reference the steady poloidal beta $\left(\square_{p}\right)$ was $\sim 1.2$ (bootstrap current fraction 40-50\%) and the line-average density relative to Greenwald scaling ${ }^{11}\left(\mathrm{n}_{\mathrm{GW}}=\mathrm{I}_{\mathrm{p}} / \square \mathrm{a}^{2}\right)$ was 0.85 just before the end of the discharge, which was terminated by $\mathrm{I}_{\mathrm{p}}$ ramp-down. We note that details of this high performance regime for similar discharges have been reported previously ${ }^{12-15}$. The new discovery presented in this paper pertains to 1 ) the positive identification of the $D_{\square}$ oscillations as tiny ELMs, which are different from ELMs in the published literature, and 2) the recent observation of conventional Type III ELMs in NSTX which confirm the uniqueness of these type V ELMs.

ELM characteristics - As mentioned previously, these type V ELMs have no measurable impact on stored energy, but they are observed both in the divertor $\mathrm{D}_{\square}$ radial profile and also on the ultra-soft X-rays (USXR - see fig. 3 and following paragraphs for viewing geometry). Fig. 2 shows the stored energy computed from reconstructions with the EFITD code $^{16}$ applied to $\mathrm{NSTX}^{17}$ with a $0.25 \mathrm{~ms}$ time resolution over a narrow time window with several type V ELMs. The direct impact of each ELM is less than the 
statistical error of $+/-1 \%$. The ELMs increase the entire divertor profile by $\sim 20-30 \%$, similar to the impact observed in the spatially integrated channel in panel 1(b). Note that that these ELMs are not the result of a coherent MHD mode. Low-n intermediate frequency (20-40 kHz) coherent modes are observed in the core from 300-700 msec, but these modes start after the type V ELM activity. In other discharges it was observed that these coherent modes persist even after the ELMs stop. Thus it is clear that the coherent modes are not the source of the ELMs.

Insight into the ELM size, affected spatial depth and spatial origin can be obtained through examination of the USXR data ${ }^{18}$. At the time of these experiments, three arrays were implemented on NSTX: one each looking into the lower and upper divertors, and one looking from the top across the entire poloidal cross section (fig. 3). The chords are spaced approximately $3 \mathrm{~cm}$ apart, and $5 \square \mathrm{m}$ Be foil filters were used to focus on emission from the edge of the plasma for the lower divertor and vertical arrays, whereas the upper divertor array had a $100 \square \mathrm{m}$ Be foil filter to focus on core USXR emission. The data were sampled at $190 \mathrm{kHz}$. For the vertical array, the chord numbering starts at 0 for the chord nearest the outer midplane and increases to 17 for the chord nearest the inner midplane. For the lower divertor array, the chord numbering starts at 0 for the lowest chord and increases to 15 for the chord near the midplane. A thick filter was used on the upper divertor array to verify that the ELMs did not extend into the core. Fig. 4a shows the relative change in intensity before and during a typical type V ELM. For reference, the statistical variability in the USXR signal is between 1-2\% for this time, so relative changes in intensity of $>2 \%$ are significant. It can be seen that the chords $1-4$ show the most significant change due to the ELM. Note that all USXR data presented here are lineintegrated measurements, so changes in the edge chord emission are also seen to a lesser extent on adjoining chords. Hence the affected region is either one or two chords, i.e. a very narrow region of the plasma on the outboard side. Fig. $4 \mathrm{~b}$ shows a (contrast enhanced) contour plot of several Type V ELMs from the vertical array. Note that the oscillation (e.g. the event near $\mathrm{t}=0.444 \mathrm{~s}$ ) first appears on $\sim$ chord 5 , and propagates to chord 0 and then disappears for a few 10s of $\square$ s. Fig. $4 \mathrm{c}$ shows the same events on the lower divertor array. In the time the perturbation disappears from the view of the vertical array, it appears in $\sim$ chord 4 of the lower divertor array and then propagates rapidly to chord 15. Shortly after disappearing from the lower divertor array, the ELM reappears in 
chord 0 of the vertical array and propagates to chord 5 before dissipating. The geometry of the vertical array misses the plasma at the outer midplane, hence the disappearance of the ELM on that array signifies propagation to the outer midplane at the time. Simple triangulation indicates that the ELM begins in the lower divertor region, possibly in the vicinity of the X-point, and then propagates with a poloidal component to the outer midplane and then back around to the top of the machine. This poloidal component of the propagation is also observed by a Mirnov array in the NSTX passive stabilizing plates. The duration of this perturbation on the USXR is $\sim 200 \square \mathrm{s}$, and the USXR perturbation precedes the divertor $D_{\square}$ light enhancement by a few $100 \square \mathrm{s}$, indicating that the diagnostics indeed observe the same perturbation, the USXR on closed field lines and then the $\mathrm{D}_{\square}$ after the perturbation crosses the separatrix to open field lines. At the onset of the perturbation in the USXR, a rotating mode with toroidal mode number $n=1$ is observed in the lower divertor toroidal Mirnov array, persisting for up to 1-2 toroidal transit times and propagating in the counter $\mathrm{I}_{\mathrm{p}}$ direction. We note that, on occasion, type V ELMs have been observed to originate near the top of the machine and propagate toward the inner midplane, i.e. also in the counter $I_{p}$ direction. The spatial origin is significant because the perturbation clearly does not originate at the outer midplane.

Particle control aspects - One critical question is the ability of these small ELMs to provide sufficient density and impurity control. Experimentally it is observed that the edge carbon density and radiation increases during these discharges, but the core radiated power and impurity content remain low. Part of the density rise may occur due to continuous fueling from the center stack gas injection system, which has a $\sim 500 \mathrm{~ms}$ efolding on the fueling rate after activation. The density rise from \#108729 was examined via a simple particle balance mode $1^{19,20}$ to obtain an estimate of particle containment time $\square_{p}^{*} \sim 0.5 \mathrm{~s}$, yielding a ratio of particle to energy containment of $\square_{p}^{*} / \square_{E} \sim 9$. This value is approximately the same value obtained in DIII-D long pulse H-modes before active divertor pumping was enabled; the DIII-D ratio was reduced $\sim 50 \%$ (by reducing $\square_{p}^{*}$ ) with efficient in-vessel cryo-pumping (i.e. line average density was reduced by at least a factor of 2$)^{21}$. We also note that the density rises even more quickly in NSTX ELM-free discharges than in discharges with type V ELMs. Thus it is probable that NSTX could 
achieve a similar reduction in $\square_{p}^{*} / \square_{E}$ with an efficient active pumping scheme, implying that the particle confinement reduction provided by these ELMs will allow for sufficient density control.

Summary, Discussion and Conclusions - We have observed a high performance regime in NSTX which is compatible with tiny ELMs with a frequency $\sim 300-800 \mathrm{~Hz}$. The stored energy drop per type V ELM is not statistically measurable, i.e. $<1 \%$. The perturbations are visible in the ultra-soft X-ray diagnostic, which precedes the $\mathrm{D}_{\square}$ burst in the divertor. The USXR bursts originate usually in the lower divertor, and at other times near the top of the machine. There is no clear $\mathrm{P}_{\mathrm{NBI}}$ scaling, although these ELMs disappear and Type III ELMs ${ }^{8}$ are sometimes observed with $\mathrm{P}_{\mathrm{NBI}}<2.5 \mathrm{MW}$. These ELMs are observed with $\mathrm{P}_{\mathrm{NBI}}$ up to $6.2 \mathrm{MW}$, and occasionally larger (possibly Type I) ELMs coexist with these ELMs. There are clear electromagnetic signatures but no electromagnetic pre-cursors to type V ELMs.

These type V ELMs have clear differences compared with published ELM types ${ }^{8}$ and ELM theories ${ }^{22,23}$. Type I ELMs are thought to occur near the ideal first stability limit, increase in frequency with $\mathrm{P}_{\mathrm{NBI}}$, and typically cause a $\sim 5-10 \%$ reduction in stored energy. Type II ELMs are observed ${ }^{24}$ at low shaping factor $\mathrm{S} / \mathrm{q}_{95}{ }^{2}<0.15$, i.e. for DIII-D parameters when $\square>1.85$ and $\square>0.4$. These NSTX parameters have shaping parameters in that range, and while this ELM type has some similarities with NSTX Type V ELM observations, the $\mathrm{q}_{95}$ term is a generalization, i.e. the important parameter is local field line pitch in the instability region (e.g. outer midplane). The edge field line pitch $\left(\mathrm{B}_{\square} / \mathrm{B} \mid\right)$ in NSTX approaches 0.35 in these discharges, i.e. the local $q$ is much lower than a conventional aspect ratio tokamak (in other words, the high $\mathrm{q}_{95}$ obtained is largely the result of field lines wrapping around the centers $\operatorname{stack}^{25}$ ). From this argument, it is expected that the equivalent $\mathrm{S} / \mathrm{q}_{95}{ }^{2}$ threshold for a spherical tokamak for type II ELMs would be lower than a conventional aspect ratio tokamak by roughly $1 /(1-\mathrm{R} / \mathrm{a})$ if the same physics applies. Type III ELMs are thought to be resistive modes, with clear electromagnetic pre-cursors and degraded performance. A low density branch ${ }^{26}$ of the traditionally high density type III ELMs were observed in DIII-D and referred to as Type IV ELMs in the community. The NSTX type V ELMs are observed at medium to high density (between 0.5 and $1 \mathrm{X} \mathrm{n}_{\mathrm{GW}}$ ) and have no clear electromagnetic pre-cursors. The 
leading theory to explain most ELMs is a combination peeling mode/ballooning mode theory leading to intermediate $\mathrm{n}$ (between 10 and 30) modes, but the instability location is the low-field side, i.e. the outer midplane ${ }^{22,23}$. The spatial location of the instability location in type V ELMs suggests a potential link to resistive ballooning modes modified by an X-point geometry ${ }^{27}$.

Type V ELMs clearly do not fit into the classical ELM picture. Their compatibility with high performance plasmas and the calculations showing that density control would be possible with active pumping make this operating regime an attractive possibility for next generation devices. Extrapolation of this regime to conventional aspect ratio tokamaks and a theoretical explanation of the ELM instability mechanism are being explored.

Acknowledgements - This research was supported by the U. S. Dept. of Energy under contracts DE-AC05-00OR22725, DE-AC02-76CH03073 and W-7405-ENG-36, and grants DE-FG02-99ER54519, DE-FG02-99ER54523, and DE-FG02-99ER54524, We gratefully acknowledge the contributions of the NSTX operations staff. 


\section{Figure Captions}

1. High performance discharge with Type V ELMs: (a) $\mathrm{I}_{\mathrm{p}}$ and $\mathrm{P}_{\mathrm{NBI}}$, (b) line-averaged density $\left(\mathrm{n}_{\mathrm{e}}\right)$ and lower divertor $\mathrm{D}_{\square}$ emission, (c) NBI $\left(\mathrm{S}_{\mathrm{NBI}}\right)$ and gas $\left(\mathrm{S}_{\mathrm{gas}}\right)$ fueling rates, and density rise rate $\left(\mathrm{dN}_{\mathrm{e}} / \mathrm{dt}\right),(\mathrm{d})$ stored energy $\left(\mathrm{W}_{\mathrm{MHD}}\right)$ and energy confinement normalized to the ITER-89P scaling. The Type V ELMs start at $\mathrm{t} \sim 0.34 \mathrm{~s}$ as indicated by the vertical line.

2. ELMs are observed on (a) edge USXR, and (b) divertor $\mathrm{D}_{\square}$, but not directly on (c) stored energy.

3. USXR view geometry for \#108729@0.35 s.

4. USXR view of divertor ELM: (a) change in intensity before/during ELM, (b) contour plot of vertical USXR showing ELM propagation, and (c) contour plot of lower divertor USXR showing ELM propagation. 
Figure 1

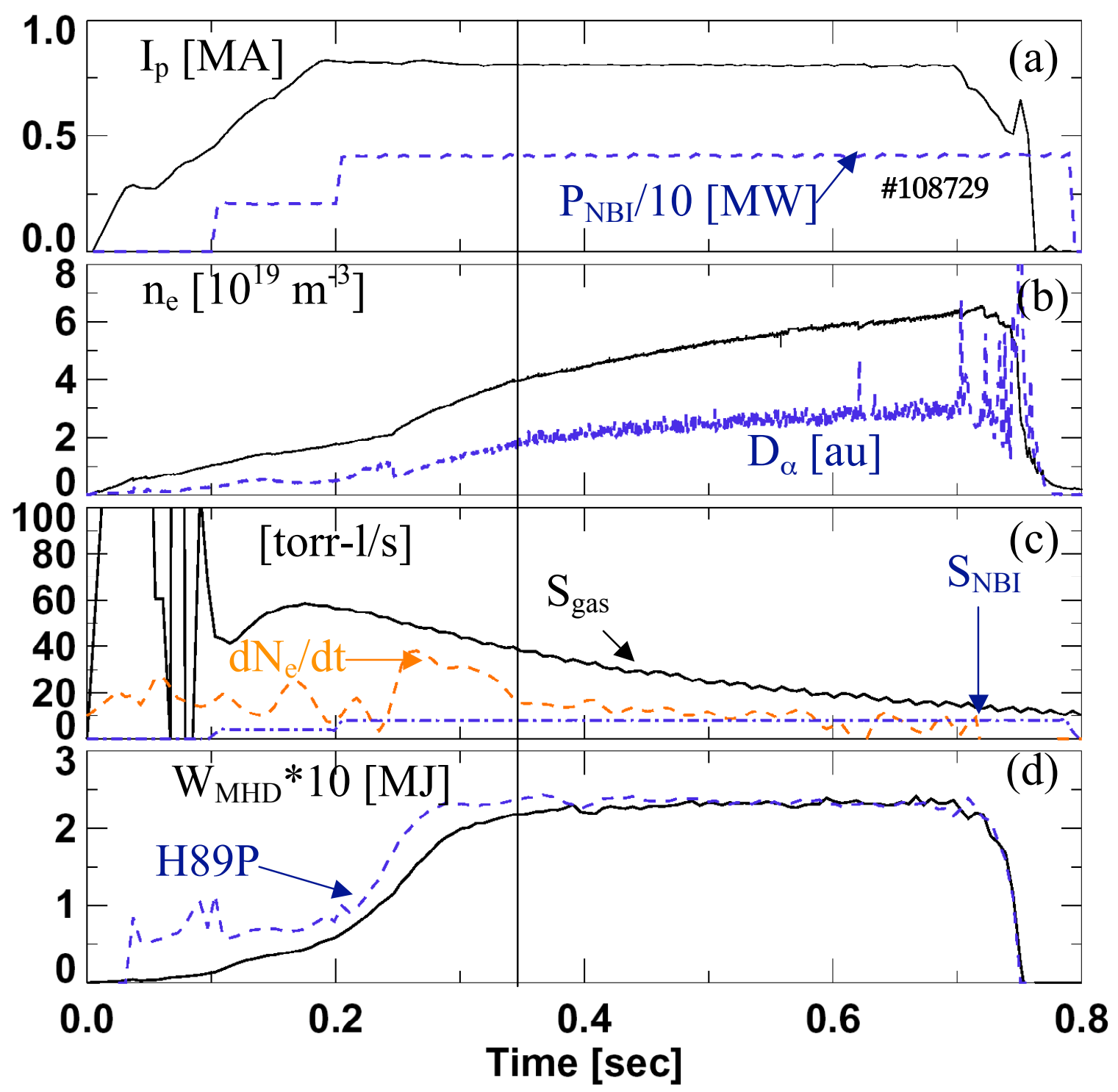


Figure 2

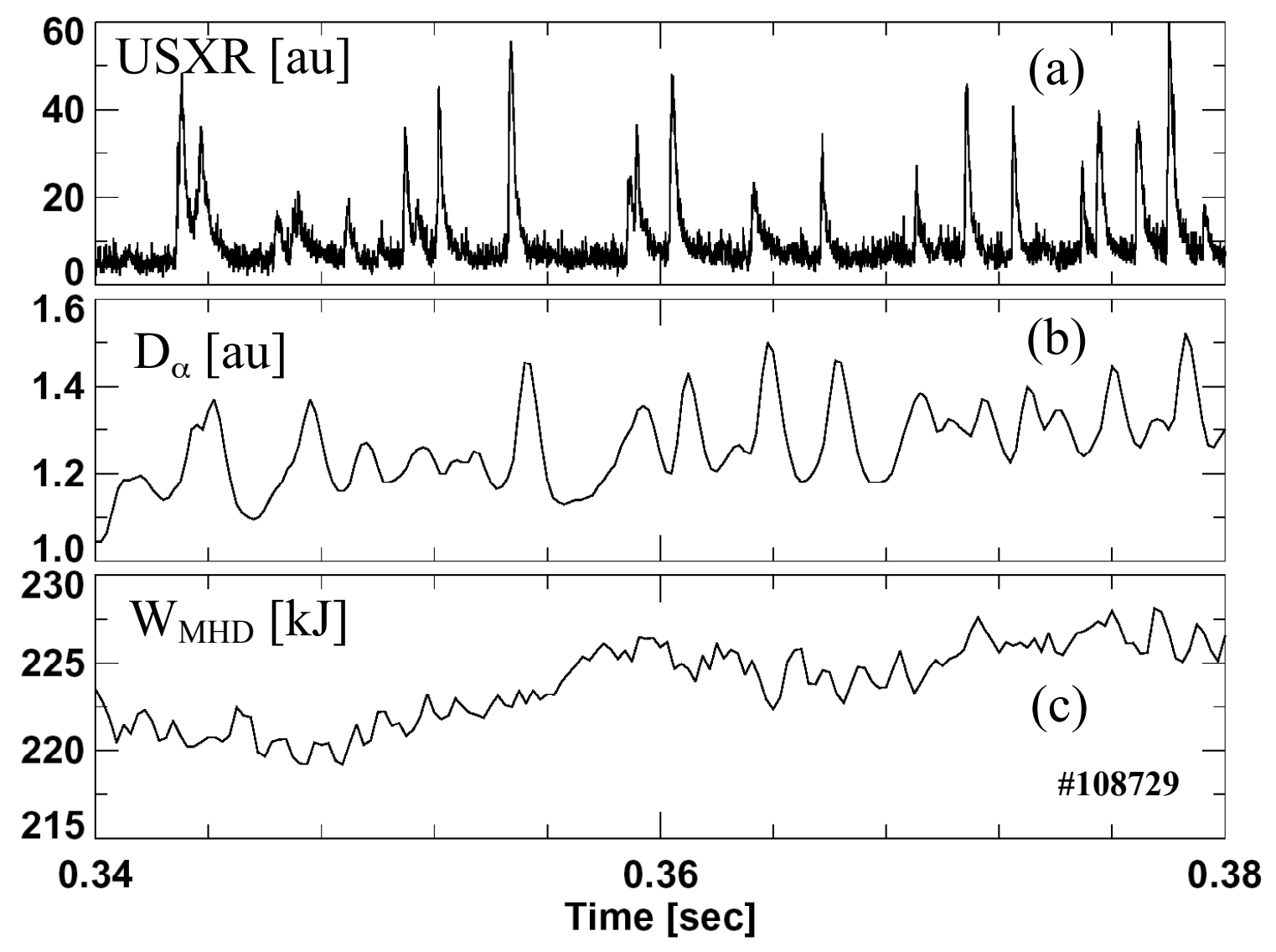


Figure 3

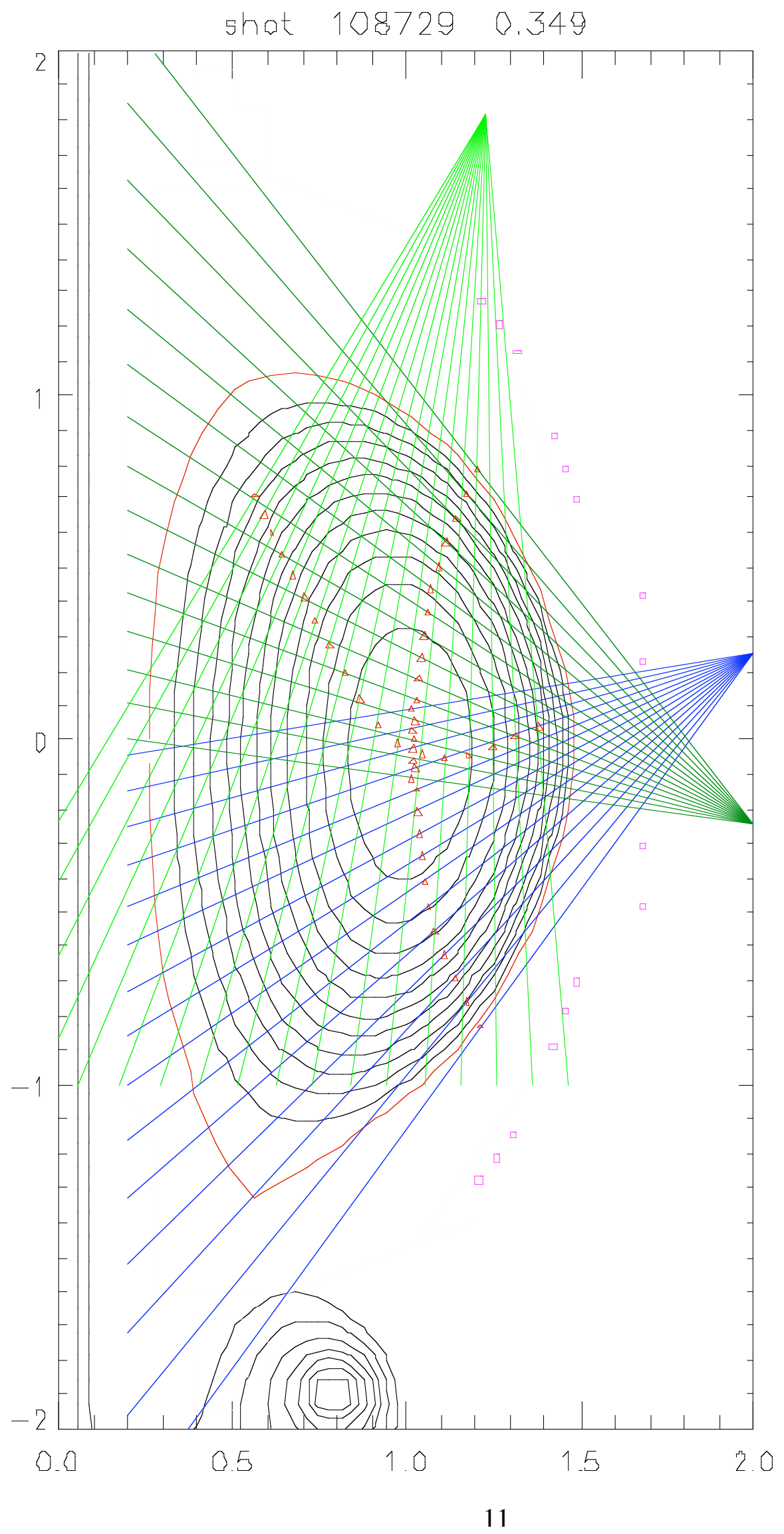


Figure 4a - SXR picture of outboard Type V ELM (from \#108730)

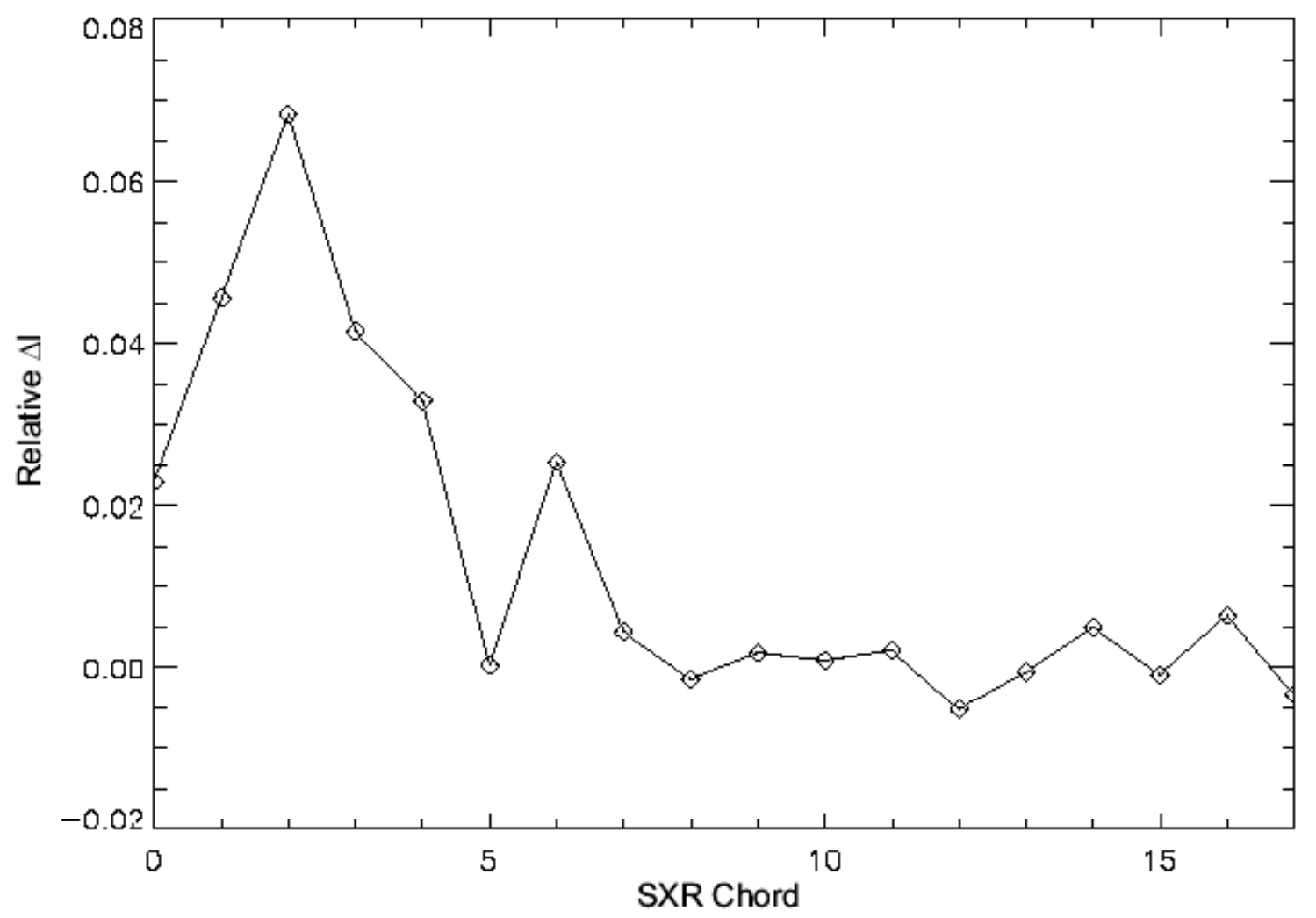

Outboard

Center

Inboard 
Figure 4b,c (USXR top, lower divertor contours)
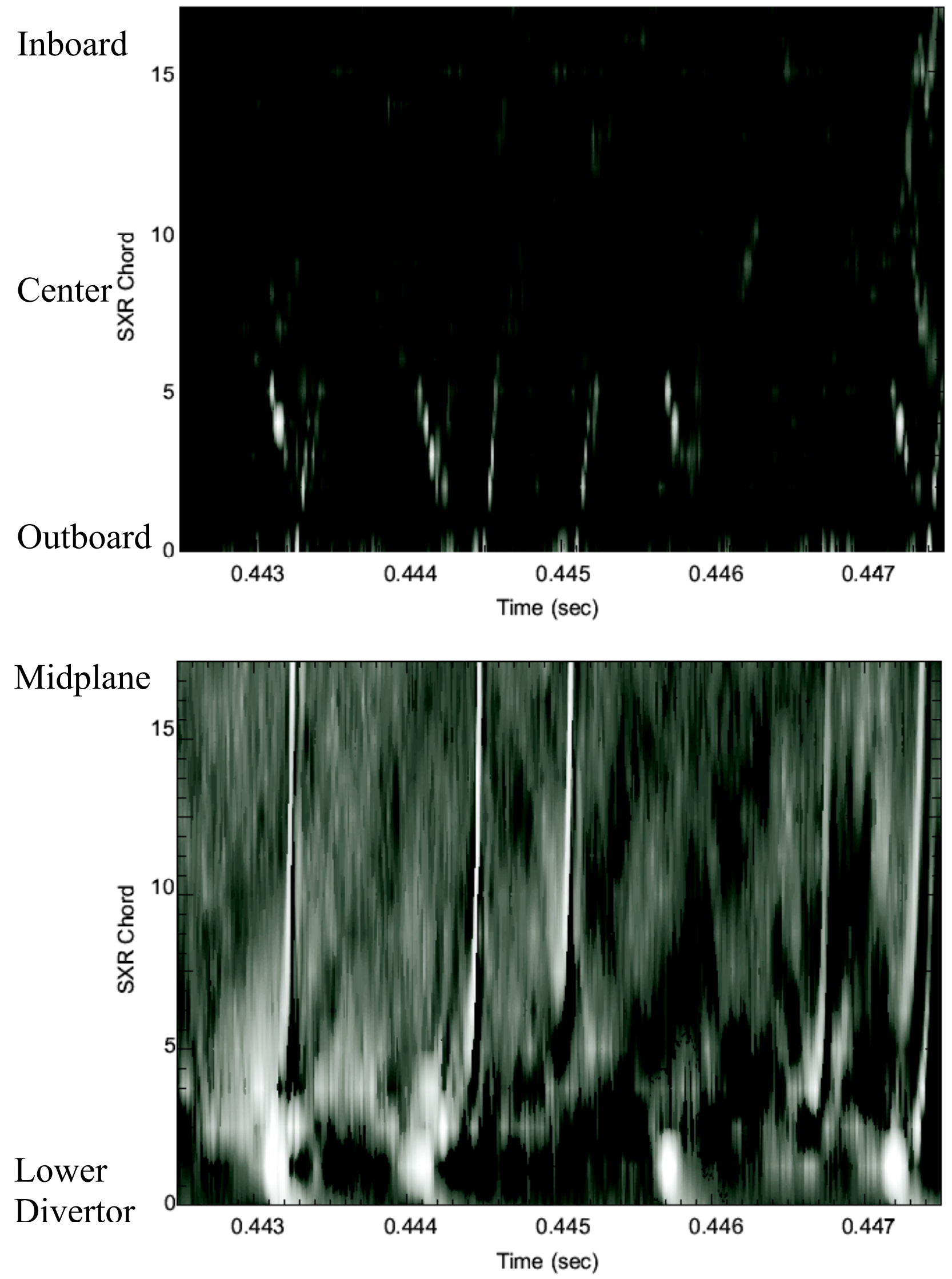


\section{References}

$1 \quad$ I. P. B. Authors, et. al., Nuclear Fusion 39, 2137 (1999).

A. Loarte, et. al., J. Nucl. Materials 313-316, 962 (2003).

G. Federici, et. al., J. Nucl. Materials 313-316, 11 (2003).

C. M. Greenfield, et. al., Physical Review Letters 86, 4544 (2001).

Y. Takase, et. al., Physics of Plasmas 4, 1647 (1997).

S. M. Kaye, et. al., J. Nucl. Materials 121, 115 (1984).

T. E. Evans, et. al., Physical Review Letters at press (2004).

E. J. Doyle, et. al., Physics of Fluids B 3, 2300 (1991).

M. Ono, et. al., Nuclear Fusion 40, 557 (2000).

P. N. Yushmanov, et. al., Nuclear Fusion 30, 1999 (1990).

M. Greenwald, et. al., Nuclear Fusion 28, 2199 (1988).

D. A. Gates, et. al., Physics of Plasmas 10, 1659 (2003).

J. E. Menard, et. al., Nuclear Fusion 43, 330 (2003).

R. Maingi, et. al., Plasma Physics Controlled Fusion 45, 657 (2003).

S. A. Sabbagh, et. al., Physics of Plasmas 9, 2085 (2002).

L. L. Lao, et. al., Nuclear Fusion 25, 1611 (1985).

S. A. Sabbagh, et. al., Nuclear Fusion 41, 1601 (2001).

D. Stutman, et. al., Review of Scientific Instruments 74, 1982 (2003).

G. L. Jackson, et. al., J. Nucl. Materials 196-198, 236 (1992).

R. Maingi, et. al., J. Nucl. Materials (submitted, 5/04).

M. A. Mahdavi, et. al., J. Nucl. Materials 220-222, 13 (1995).

P. B. Snyder, et. al., Physics of Plasmas 9, 2037 (2002).

H. R. Wilson, et. al., Physics of Plasmas 9, 1277 (2002).

T. Ozeki, et. al., Nuclear Fusion 30, 1425 (1990).

Y.-K. M. Peng, et. al., Nuclear Fusion 26, 769 (1986).

T. H. Osborne, et. al., Proc. of the 24th European Conference on Controlled

Fusion and Plasma Physics, Berchtesgaden, Germany 1997 (EPS, Petit-

Lancy, Switzerland) (1997).

$27 \quad$ X. Q. Xu, et. al., Physics of Plasmas 7, 1951 (2000). 


\section{External Distribution}

Plasma Research Laboratory, Australian National University, Australia

Professor I.R. Jones, Flinders University, Australia

Professor João Canalle, Instituto de Fisica DEQ/IF - UERJ, Brazil

Mr. Gerson O. Ludwig, Instituto Nacional de Pesquisas, Brazil

Dr. P.H. Sakanaka, Instituto Fisica, Brazil

The Librarian, Culham Laboratory, England

Mrs. S.A. Hutchinson, JET Library, England

Professor M.N. Bussac, Ecole Polytechnique, France

Librarian, Max-Planck-Institut für Plasmaphysik, Germany

Jolan Moldvai, Reports Library, Hungarian Academy of Sciences, Central Research Institute for Physics, Hungary

Dr. P. Kaw, Institute for Plasma Research, India

Ms. P.J. Pathak, Librarian, Institute for Plasma Research, India

Ms. Clelia De Palo, Associazione EURATOM-ENEA, Italy

Dr. G. Grosso, Instituto di Fisica del Plasma, Italy

Librarian, Naka Fusion Research Establishment, JAERI, Japan

Library, Laboratory for Complex Energy Processes, Institute for Advanced Study, Kyoto University, Japan

Research Information Center, National Institute for Fusion Science, Japan

Dr. O. Mitarai, Kyushu Tokai University, Japan

Dr. Jiangang Li, Institute of Plasma Physics, Chinese Academy of Sciences, People's Republic of China

Professor Yuping Huo, School of Physical Science and Technology, People's Republic of China

Library, Academia Sinica, Institute of Plasma Physics, People's Republic of China

Librarian, Institute of Physics, Chinese Academy of Sciences, People's Republic of China

Dr. S. Mirnov, TRINITI, Troitsk, Russian Federation, Russia

Dr. V.S. Strelkov, Kurchatov Institute, Russian Federation, Russia

Professor Peter Lukac, Katedra Fyziky Plazmy MFF UK, Mlynska dolina F-2, Komenskeho Univerzita, SK-842 15 Bratislava, Slovakia

Dr. G.S. Lee, Korea Basic Science Institute, South Korea

Institute for Plasma Research, University of Maryland, USA

Librarian, Fusion Energy Division, Oak Ridge National Laboratory, USA

Librarian, Institute of Fusion Studies, University of Texas, USA

Librarian, Magnetic Fusion Program, Lawrence Livermore National Laboratory, USA

Library, General Atomics, USA

Plasma Physics Group, Fusion Energy Research Program, University of California at San Diego, USA

Plasma Physics Library, Columbia University, USA

Alkesh Punjabi, Center for Fusion Research and Training, Hampton University, USA

Dr. W.M. Stacey, Fusion Research Center, Georgia Institute of Technology, USA

Dr. John Willis, U.S. Department of Energy, Office of Fusion Energy Sciences, USA

Mr. Paul H. Wright, Indianapolis, Indiana, USA 
The Princeton Plasma Physics Laboratory is operated by Princeton University under contract with the U.S. Department of Energy.

\author{
Information Services \\ Princeton Plasma Physics Laboratory \\ P.O. Box 451 \\ Princeton, NJ 08543
}

Phone: 609-243-2750

Fax: 609-243-2751

e-mail: pppl_info@pppl.gov

Internet Address: http://www.pppl.gov 